\title{
Revision of the Model of Formation of Radiolytic Products in Aqueous Solutions
}

\author{
S.V. Stepanov* And V.M. Byakov \\ Institute for Theoretical and Experimental Physics, 117218 Moscow, Russia \\ Mathematical model of formation of radiolytic products $\left(\mathrm{e}_{\mathrm{aq}}^{-}, \mathrm{H}, \mathrm{OH}\right.$, \\ $\mathrm{H}_{2}, \mathrm{H}_{3} \mathrm{O}^{+}, \mathrm{OH}^{-}, \mathrm{Ps}$ ) in water is developed. It takes into account (1) reac- \\ tions between dissolved scavengers of thermalized and hydrated electrons as \\ well as epithermal ones; (2) ambipolar diffusion expansion of the intratrack \\ species; (3) additional channels of $\mathrm{Ps}$ and $\mathrm{H}_{2}$ formation due to appearance \\ of weakly trapped electrons. Good agreement is obtained with experimental \\ data on kinetics of accumulation of the products in pure water and their \\ concentration variations in aqueous solutions.
}

PACS numbers: 61.80.Fe, 36.10.Dr, 78.70.Bj

\section{Introduction}

In this paper we develop a model for calculation of the yields of radiolytic products in tracks of fast electrons and positrons in water and aqueous solutions $[1-3]$. The model suggests a similarity of physico-chemical processes in tracks of these particles and is aimed on a unified interpretation of radiation-chemical as well as positron spectroscopy data. We consider the processes on $10^{-12}-10^{-6} \mathrm{~s}$. Together with conventional radiolytic products $\mathrm{e}_{\mathrm{aq}}^{-}, \mathrm{H}, \mathrm{OH}$, and $\mathrm{H}_{3} \mathrm{O}^{+}$, we take into consideration their short-lived precursors: quasi-free electron, $\mathrm{e}^{-}$, and radical-cation $\mathrm{H}_{2} \mathrm{O}^{+}$. We assume that reactions in different tracks take place independently (no track overlapping). Because large spurs (blobs), containing many ion-electron pairs, mostly contribute to formation of recombination products, it is natural to formulate the problem in terms of differential equations on concentrations of reagents. For simplicity we adopt that tracks of fast $\mathrm{e}^{-}$and $\mathrm{e}^{+}$ consist of identical spherically-symmetric fragments with the same initial number of ion-electron pairs, $n_{0}$, simulating spurs and blobs.

We shall test the model using experimental data on the yields of $\mathrm{H}_{2}, \mathrm{e}_{\mathrm{aq}}^{-}, \mathrm{OH}$, and $\mathrm{Ps}$ in aqueous solutions vs. time and concentration of $\mathrm{NO}_{3}^{-}, \mathrm{H}_{2} \mathrm{O}_{2}, \mathrm{HClO}_{4}$, and $\left(\mathrm{CH}_{3}\right)_{2} \mathrm{CO}$. Table I summarizes taken into account chemical reactions and respective rate constants.

*corresponding author; e-mail: Sergey.Stepanov@itep.ru 
TABLE I

Primary radiation-chemical reactions and their rate constants. ${ }^{*}$

\begin{tabular}{|c|c|}
\hline $\begin{array}{l}\text { Ionization and electronic excitations: } \\
\mathrm{e}^{+* *}+\mathrm{H}_{2} \mathrm{O} \rightarrow\left\{\begin{array}{l}\mathrm{e}^{+*}+\mathrm{e}^{-*}+\mathrm{H}_{2} \mathrm{O}^{*} \\
\mathrm{e}^{+*}+\mathrm{H}_{2} \mathrm{O}^{*}\end{array}, \mathrm{H}_{2} \mathrm{O}^{*} \rightarrow\right.\end{array}$ & $\left\{\begin{array}{l}\mathrm{H}_{2} \mathrm{O} \\
\mathrm{H}+\dot{\mathrm{OH}}\end{array}, G_{\mathrm{H}_{\alpha}} \approx 0.4(1) \mathrm{H} / 100 \mathrm{eV}\right.$ \\
\hline $\begin{array}{l}\text { (Sub)picosecond stage: } \\
\mathrm{e}^{-*} \stackrel{t_{\mathrm{th}}}{\longrightarrow} \mathrm{e}^{-} \stackrel{\tau_{\mathrm{e}}^{\mathrm{aq}}}{\longrightarrow} \mathrm{e}_{\mathrm{aq}}^{-}, \mathrm{e}^{+*} \stackrel{t_{\mathrm{th}}}{\longrightarrow} \mathrm{e}^{+} \\
\mathrm{e}^{-}+\mathrm{H}_{2} \mathrm{O}^{+\cdot} \stackrel{k_{i \mathrm{e}}}{\longrightarrow} \mathrm{H}_{2} \mathrm{O}^{*}\left(+\mathrm{H}_{2} \mathrm{O}\right) \stackrel{f_{\mathrm{H}_{2}}}{\longrightarrow} \mathrm{H}_{2}+2 \mathrm{O} \mathrm{H} \\
\mathrm{H}_{2} \mathrm{O}^{+\cdot}+\mathrm{H}_{2} \mathrm{O} \stackrel{\tau_{i \mathrm{mr}}}{\longrightarrow} \dot{\mathrm{O}}+\mathrm{H}_{3} \mathrm{O}^{+} \\
\mathrm{e}^{-}+\dot{\mathrm{O}} \rightarrow \mathrm{OH}^{-} \\
\mathrm{e}^{-}+\mathrm{NO}_{3}^{-} \rightarrow \mathrm{NO}_{3}^{2-} \\
\mathrm{e}^{-}+\mathrm{H}_{2} \mathrm{O}_{2} \rightarrow \mathrm{H}_{2} \mathrm{O}_{2}^{-} \rightarrow \dot{\mathrm{O}}+\mathrm{OH}^{-} \\
\mathrm{e}^{-}+\mathrm{ClO}_{4}^{-} \rightarrow \mathrm{ClO}_{4}^{2-} \\
\mathrm{e}^{-}+\mathrm{Ac}^{-} \mathrm{Ac}^{-} \\
\mathrm{e}_{\mathrm{th}}^{+}+\mathrm{e}_{\mathrm{th}}^{-} \rightarrow \mathrm{qf}-\mathrm{Ps}_{\mathrm{s}} \\
\mathrm{e}_{\mathrm{th}}^{+}+\mathrm{e}_{\mathrm{aq}}^{-} \rightarrow \mathrm{qf}-\mathrm{Ps} \\
\mathrm{e}_{\mathrm{th}}^{+}+\mathrm{Ac}^{-} \rightarrow \mathrm{qf}-\mathrm{Ps}+\mathrm{Ac} \\
\mathrm{H}_{2} \mathrm{O}^{+\cdot}+\mathrm{Ac}^{-} \rightarrow \mathrm{H}_{2} \mathrm{O}^{*}+\mathrm{Ac} \stackrel{f_{\mathrm{H}_{2}}^{\longrightarrow}}{\longrightarrow} \mathrm{H}_{2}+\ldots\end{array}$ & $\begin{array}{l}t_{\mathrm{th}} \approx 0.12 \mathrm{ps}, \tau_{\mathrm{e}}^{\mathrm{aq}}=0.3 \mathrm{ps} \\
f_{\mathrm{H}_{2}} \approx 0.165, k_{i \mathrm{e}} \tau_{\mathrm{e}}^{\mathrm{aq}}=47-54 \mathrm{M}^{-1} \\
\tau_{i \mathrm{mr}} \approx 10 \tau_{\mathrm{e}}^{\mathrm{aq}} \\
k_{\mathrm{eOH}}=0 \\
k_{\mathrm{eNO}_{3}^{-}} \cdot \tau_{\mathrm{e}}^{\mathrm{aq}}=2.1(2) \mathrm{M}^{-1} \\
k_{\mathrm{eH}_{2} \mathrm{O}_{2}} \cdot \tau_{\mathrm{e}}^{\mathrm{aq}}=0.50(3) \mathrm{M}^{-1} \\
k_{\mathrm{eClO}} \cdot \tau_{\mathrm{e}}^{\mathrm{aq}}=0.08-0.09 \mathrm{M}^{-1} \\
k_{\mathrm{eAc}} \cdot \tau_{\mathrm{e}}^{\mathrm{aq}}=0.6-0.7 \mathrm{M}^{-1} \\
k_{\mathrm{ep}} \cdot \tau_{\mathrm{e}}^{\mathrm{aq}}=36-42 \mathrm{M}^{-1} \\
k_{\mathrm{hp}} \cdot \tau_{\mathrm{e}}^{\mathrm{aq}}=0.04-0.06 \mathrm{M}^{-1} \\
k_{\mathrm{pAc}} \cdot \cdot \tau_{\mathrm{e}}^{\mathrm{aq}}=0.01-0.05 \mathrm{M}^{-1} \\
k_{i \mathrm{Ac}}-\cdot \tau_{\mathrm{e}}^{\mathrm{aq}} \lesssim 0.01 \mathrm{M}^{-1}\end{array}$ \\
\hline 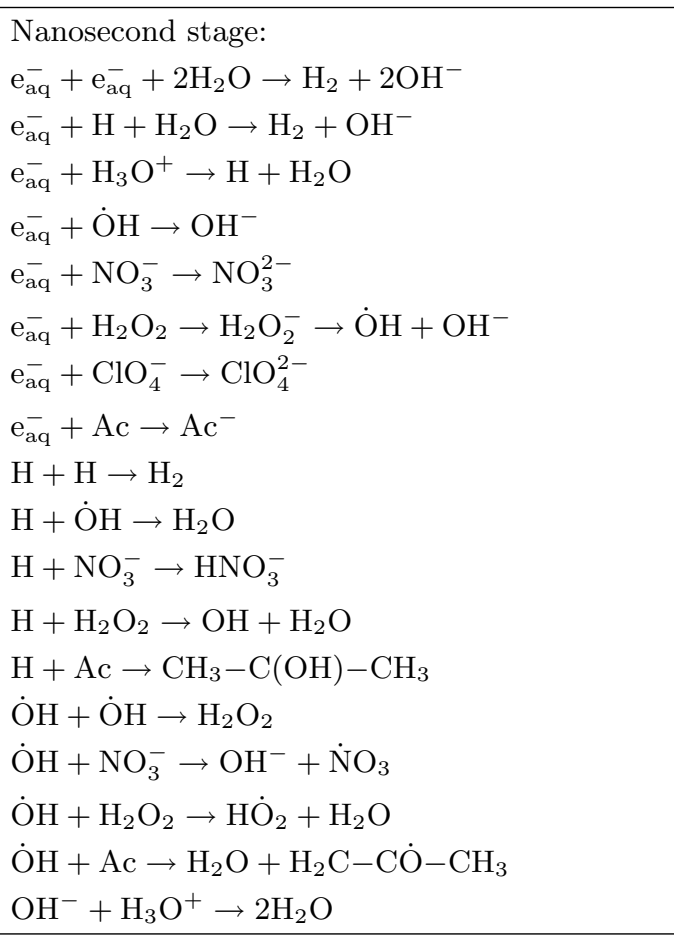 & $\begin{array}{l}\text { Rate constant }\left[\mathrm{M}^{-1} \mathrm{~s}^{-1}\right] \\
k_{\mathrm{hh}}=5.5 \times 10^{9} \\
k_{\mathrm{hH}}=2.5 \times 10^{10} \\
k_{\mathrm{hH}}+\mathrm{O}=2.3 \times 10^{10} \\
k_{\mathrm{hOH}}=3.0 \times 10^{10} \\
k_{\mathrm{hNO}_{3}^{-}}=9.2 \times 10^{9} \\
k_{\mathrm{hH}_{2} \mathrm{O}_{2}}=1.1 \times 10^{10} \\
k_{\mathrm{hClO}}=10^{5} \\
k_{\mathrm{hAc}}=6.6 \times 10^{9} \\
k_{\mathrm{H} \mathrm{H}}=5.0 \times 10^{9} \\
k_{\mathrm{H} \mathrm{OH}}=2.0 \times 10^{10} \\
k_{\mathrm{H} \mathrm{NO}}=1.0 \times 10^{7} \\
k_{\mathrm{H} \mathrm{H}} \mathrm{O}_{2}=9.0 \times 10^{7} \\
k_{\mathrm{H} \mathrm{Ac}}=2.0 \times 10^{6} \\
k_{\mathrm{OH} \mathrm{OH}}=5.5 \times 10^{9} \\
k_{\mathrm{OH} \mathrm{NO}}=1.4 \times 10^{8} \\
k_{\mathrm{OH} \mathrm{H}} \mathrm{O}_{2}=2.7 \times 10^{7} \\
k_{\mathrm{OH} \mathrm{Ac}}=8.8 \times 10^{7} \\
k_{\mathrm{OH}} \mathrm{H}_{3} \mathrm{O}+=2.0 \times 10^{11}\end{array}$ \\
\hline
\end{tabular}

${ }^{*}$ http://www.rcdc.nd.edu 
We suggest that formation of $\mathrm{H}$ atoms proceeds in two ways. The first one cannot be suppressed by presence of track electron scavengers even in a high concentration. This yield, $G_{\mathrm{H}_{\alpha}}$, is equal to $0.3-0.4 \mathrm{H}$ atoms per $100 \mathrm{eV}$ (Fig. 1), and probably is formed due to decay of primary electronic excitations of water. Precursors of the other part of the $\mathrm{H}$ atom yield are intratrack electrons: $\mathrm{e}_{\mathrm{aq}}^{-}+\mathrm{H}_{3} \mathrm{O}^{+} \rightarrow \mathrm{H}+\mathrm{H}_{2} \mathrm{O}$. This fraction of $\mathrm{H}$ atoms may be inhibited.

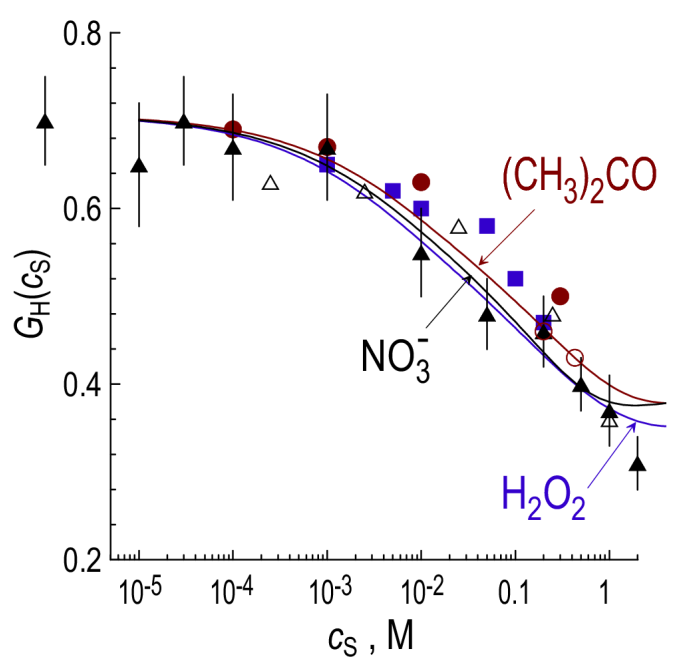

Fig. 1. H-atom yield in aqueous solutions $\mathrm{NO}_{3}^{-}(\boldsymbol{\Delta}-[4] ; \Delta-[5]), \mathrm{H}_{2} \mathrm{O}_{2}(\boldsymbol{-}-[1])$ and acetone $(\mathrm{O}-[6] ; \bullet-[5])$. Solid curves represent Eq. (9).

We assume that in subpicosecond time interval $\mathrm{H}_{2}$ is formed as a result of recombination of $\mathrm{e}^{-}$with radical-cations $\mathrm{H}_{2} \mathrm{O}^{+}$. In nanosecond stage $\mathrm{H}_{2}$ arises because of reactions $\mathrm{e}_{\mathrm{aq}}^{-}+\mathrm{e}_{\mathrm{aq}}^{-}$, $\mathrm{e}_{\mathrm{aq}}^{-}+\mathrm{H}$, and $\mathrm{H}+\mathrm{H}$. Addition of electron scavengers, in general, suppresses $\mathrm{H}_{2}$ formation.

\section{Mathematical formulation of the model and results of calculations}

We admit that scavenger may react not only with thermalized, but also with epithermal (hot) electrons. On the other hand, we believe that hydration of $\mathrm{e}^{-}$, ion-electron recombination, and Ps formation may proceed only after thermalization of $\mathrm{e}^{-}\left(\right.$at $\left.t>t_{\mathrm{th}}\right)$. Therefore in Eqs. (1), describing reactions in Table I, onset of time, $t=0$, corresponds to the beginning of the earliest intratrack reaction electron capture by the scavenger. Terms $c_{\mathrm{e}} / \tau_{\mathrm{e}}^{\text {aq }}$ and $k_{i \mathrm{e}} c_{i} c_{\mathrm{e}}$ are "switched on" by $\vartheta$-function in a proper time. When the reactions of $\mathrm{e}^{-}$with $\mathrm{OH}$ and $\mathrm{H}_{2} \mathrm{O}_{2}$ have to be "switched on" is not important, because these products are practically absent at $t<t_{\mathrm{th}}$. Thus, we shall write down equations, as follows: 


$$
\begin{gathered}
\frac{\partial c_{\mathrm{e}}}{\partial t}=D_{\mathrm{e}}(t) \Delta c_{\mathrm{e}}-\left(k_{i \mathrm{e}} c_{i}+k_{\mathrm{eOH}} c_{\mathrm{OH}}+k_{\mathrm{eH}_{2} \mathrm{O}_{2}} c_{\mathrm{H}_{2} \mathrm{O}_{2}}+\frac{1}{\tau_{\mathrm{e}}^{\mathrm{aq}}}\right) c_{\mathrm{e}} \vartheta\left(t>t_{\mathrm{th}}\right) \\
-k_{\mathrm{eS}} c_{\mathrm{e}} \tilde{c}_{\mathrm{S}} \\
c_{\mathrm{e}}(r, 0)=n_{0} \mathcal{G}\left(r, 0, a_{\mathrm{bl}}, 0\right), \mathcal{G}\left(r, 0, a_{\mathrm{bl}}, 0\right)=\frac{\exp \left(-r^{2} / a_{\mathrm{bl}}^{2}\right)}{\pi^{3 / 2} a_{\mathrm{bl}}^{3}}, \\
\frac{\partial c_{i}}{\partial t}=D_{i}(t) \Delta c_{i}-k_{i \mathrm{e}} c_{i} c_{\mathrm{e}} \vartheta\left(t>t_{\mathrm{th}}\right)-k_{i \mathrm{~S}^{-}} c_{i} c_{\mathrm{S}^{-}}-\frac{c_{i}}{\tau_{i \mathrm{mr}}}, \\
c_{i}(r, 0)=n_{0} \mathcal{G}\left(r, 0, a_{\mathrm{bl}}, 0\right), \\
\frac{\partial \tilde{c_{\mathrm{S}}}}{\partial t}=D_{\mathrm{S}}(t) \Delta \tilde{c}_{\mathrm{S}}+\left(k_{\mathrm{eS}} c_{\mathrm{e}}+k_{\mathrm{hS}} c_{\mathrm{h}}+k_{\mathrm{H} \mathrm{S}} c_{\mathrm{H}}+k_{\mathrm{OHS}} c_{\mathrm{OH}}\right) \tilde{c}_{\mathrm{S}}, \\
\tilde{c}_{\mathrm{S}}(r, 0)=c_{\mathrm{S}}
\end{gathered}
$$

and so on for all the other reagents $\left(\mathrm{S}^{-}, \mathrm{H}, \mathrm{e}_{\mathrm{aq}}^{-}, \mathrm{OH}, \mathrm{OH}^{-}, \mathrm{H}_{2} \mathrm{O}_{2}, \mathrm{H}_{3} \mathrm{O}^{+}\right)$. Here $c_{\mathrm{e}}(r, t)$ and $c_{\mathrm{h}}(r, t)$ are concentrations of quasi-free and hydrated electrons, $c_{i}(r, t)$ is the $\mathrm{H}_{2} \mathrm{O}^{+\cdot}$ concentration, $\tilde{c}_{\mathrm{S}}(r, t)$ is the concentration of the scavenger. Diffusion expansion of the particle $j$ proceeds with the diffusion coefficient $D_{j}(t)$, which may depend on $t$. Charged species $\left(\mathrm{e}^{-}, \mathrm{H}_{2} \mathrm{O}^{+}, \mathrm{e}_{\mathrm{aq}}^{-}, \mathrm{H}_{3} \mathrm{O}^{+}, \mathrm{S}^{-}\right)$at small $t$ diffuse according to ambipolar diffusion law with the same diffusion coefficient, $D_{\mathrm{amb}}$. Later on, when correlation in their positions disappears (at distances $\gtrsim a_{\mathrm{bl}}$ ), diffusion coefficients attain their individual values $\left(\mathrm{cm}^{2} / \mathrm{s}\right)[7,8]$ :

$$
\begin{array}{l|l|l}
D_{\mathrm{e}_{\mathrm{aq}}^{-}}=4.5 \times 10^{-5} & D_{\mathrm{OH}}=2.8 \times 10^{-5} & D_{\mathrm{NO}_{3}^{-}}=1.8 \times 10^{-5} \\
D_{\mathrm{H}_{3}^{+} \mathrm{O}}=9 \times 10^{-5} & D_{\mathrm{OH}^{-}}=5 \times 10^{-5} & D_{\mathrm{ClO}_{4}^{-}}=1.5 \times 10^{-5} \\
D_{\mathrm{H}}=7 \times 10^{-5} & D_{\mathrm{H}_{2} \mathrm{O}_{2}}=1.4 \times 10^{-5} & D_{\mathrm{Ac}}=1 \times 10^{-5}
\end{array}
$$

We adopted following approximation $D_{j}(t)=D_{j}+\left(D_{\mathrm{amb}}-D_{j}\right) e^{-t / t_{\mathrm{amb}}}$, where $t_{\mathrm{amb}}$ is the time during which the diffusion is ambipolar. Diffusion coefficients of neutral particles $\left(\mathrm{OH}, \mathrm{H}, \mathrm{H}_{2} \mathrm{O}_{2}\right)$ were supposed to be independent of time.

Ps formation proceeds via recombination of thermalized $\mathrm{e}^{+}$with one of the knocked out electrons (it could be either $\mathrm{e}^{-}$or $\mathrm{e}_{\mathrm{aq}}^{-}$) in the terminal part of the $\mathrm{e}^{+}$ track [3]. Therefore in equation for $\mathrm{e}^{+}$survival probability, $c_{\mathrm{p}}(r, t)$, corresponding terms are switched on by $\vartheta\left(t>t_{\mathrm{th}}\right)$ multiplier ${ }^{\dagger}$ :

$$
\begin{gathered}
\frac{\partial c_{\mathrm{p}}}{\partial t}=D_{\mathrm{p}}(t) \Delta c_{\mathrm{p}}-\left(k_{\mathrm{ep}} c_{\mathrm{e}}+k_{\mathrm{hp}} c_{\mathrm{h}}+k_{\mathrm{S}^{-} \mathrm{p}} c_{\mathrm{S}^{-}}\right) c_{\mathrm{p}} \vartheta\left(t>t_{\mathrm{th}}\right)-\lambda_{2} c_{\mathrm{p}}, \\
c_{\mathrm{p}}(r, 0)=\mathcal{G}\left(r, 0, a_{\mathrm{bl}}, 0\right) .
\end{gathered}
$$

This equation takes into account $\mathrm{e}^{+}$diffusion $\left(D_{\mathrm{p}}(t) \Delta c_{\mathrm{p}}\right)$ and annihilation of electrons of the medium $\left(-\lambda_{2} c_{\mathrm{p}}\right)$.

${ }^{\dagger}$ If the $\mathrm{e}^{-}$scavenger is weak, reaction $\mathrm{e}^{+}+\mathrm{S}^{-} \rightarrow \mathrm{Ps}+\mathrm{S}$ might be also energetically possible [9]. 
Equations (1) are solved by means of generalized prescribed diffusion method. It prescribes the following form of the solution:

$$
\begin{aligned}
c_{j}(r, t) \approx n_{j}(t) \mathcal{G}\left(r, t, a_{\mathrm{bl}}, D_{j}\right), \\
\mathcal{G}\left(r, t, a_{\mathrm{bl}}, D_{j}\right)=\frac{\exp \left[-r^{2} /\left(a_{\mathrm{bl}}^{2}+4 \int_{0}^{t} D_{j}(\tau) \mathrm{d} \tau\right)\right]}{\pi^{3 / 2}\left(a_{\mathrm{bl}}^{2}+4 \int_{0}^{t} D_{j}(\tau) \mathrm{d} \tau\right)^{3 / 2}} .
\end{aligned}
$$

Here $n_{j}(t)$ is the total number of the species " $j$ " in the blob (spur) at time moment $t$.

At the beginning $\mathrm{e}^{-}$scavenger is uniformly distributed in the bulk of the liquid. With time it burns out mainly within the blob. It can be taken into account as follows:

$$
\tilde{c}_{\mathrm{S}}(r, t) \approx c_{\mathrm{S}}-n_{\tilde{\mathrm{S}}}(t) \mathcal{G}\left(r, t, a_{\mathrm{bl}}, D_{\mathrm{S}}\right),
$$

where $n_{\tilde{\mathrm{S}}}(t)$ is the number of $\mathrm{S}$, reacting either with intratrack $\mathrm{e}^{-}$, or other radiolytic products $(\mathrm{OH}, \mathrm{H})$, i.e., it is total number of the scavenger molecules, which disappear by time $t$. In the same manner one may describe kinetics of accumulation of $\mathrm{H}_{3} \mathrm{O}^{+}$ions, if the dissolved additive is an acid

$$
c_{\mathrm{H}_{3}^{+} \mathrm{O}}(r, t) \approx c_{\mathrm{S}}+n_{\mathrm{H}_{3}^{+} \mathrm{O}}(t) \mathcal{G}\left(r, t, a_{\mathrm{bl}}, D_{\mathrm{S}}\right),
$$

where $c_{\mathrm{S}}$ is the concentration of the acid, and $n_{\mathrm{H}_{3}^{+} \mathrm{O}}(t)$ has the meaning of additional number of $\mathrm{H}_{3} \mathrm{O}^{+}$, formed (and decayed) as a result of intratrack transformations only.

Following the prescribed diffusion method we integrate Eqs. (1) for each $c_{j}(r, t)$ over whole volume. Thus we obtain a set of ordinary differential equations on $n_{j}(t)$, which is the total number of species $j$ in the blob by the time $t$. These equations are solved numerically. Finally we calculate "initial" (or picosecond) relative yield of the hydrated electron

$$
\begin{aligned}
& \frac{G_{\mathrm{e}_{\mathrm{aq}}^{-}}\left(c_{\mathrm{S}}\right)}{G_{\mathrm{e}_{\mathrm{aq}}^{-}}(0)}=\int_{0}^{\infty} n_{\mathrm{e}}(t) \frac{\mathrm{d} t}{\tau_{\mathrm{e}}^{\mathrm{aq}}} / \int_{0}^{\infty} n_{\mathrm{e}}\left(t, c_{\mathrm{S}}=0\right) \frac{\mathrm{d} t}{\tau_{\mathrm{e}}^{\mathrm{aq}}}, \\
& G_{\mathrm{H}_{2}}\left(c_{\mathrm{S}}\right)=G_{i \mathrm{ep}} \int_{0}^{\infty}\left(f_{\mathrm{H}_{2}} \frac{k_{i \mathrm{e}} n_{i} n_{\mathrm{e}}}{n_{0} V_{i \mathrm{e}}}+\frac{k_{\mathrm{hh}} n_{\mathrm{h}}^{2}}{n_{0} V_{\mathrm{hh}}}+\frac{k_{\mathrm{hH}} n_{\mathrm{h}} n_{\mathrm{H}}}{n_{0} V_{\mathrm{hH}}}+\frac{k_{\mathrm{HH}} n_{\mathrm{H}}^{2}}{n_{0} V_{\mathrm{HH}}}\right) \mathrm{d} t, \\
& \frac{I_{3}\left(c_{\mathrm{S}}\right)}{100 \%}=\frac{3}{4} \int_{t_{\mathrm{th}}}^{\infty}\left(\frac{k_{\mathrm{ep}} n_{\mathrm{e}} n_{\mathrm{p}}}{V_{\mathrm{ep}}}+\frac{k_{\mathrm{hp}} n_{\mathrm{h}} n_{\mathrm{p}}}{V_{\mathrm{hp}}}+\frac{k_{\mathrm{S}^{-} \mathrm{p}} n_{\mathrm{S}-} n_{\mathrm{p}}}{V_{\mathrm{pS}}}\right) \mathrm{d} t \\
& G_{\mathrm{H}}\left(c_{\mathrm{S}}\right)=G_{i \mathrm{ep}}\left[\frac{n_{\mathrm{H}}\left(t \approx 1 \mu \mathrm{s}, c_{\mathrm{S}}=0\right)}{n_{0}}-\frac{n_{\mathrm{H}}\left(t \approx 1 \mu \mathrm{s}, c_{\mathrm{S}} ; k_{\mathrm{HS}}=0\right)}{n_{0}}\right],
\end{aligned}
$$




$$
V_{j q}=V_{\mathrm{bl}}^{0}\left(1+t / \tau_{j q}\right)^{3 / 2}, \quad V_{\mathrm{bl}}^{0}=(2 \pi)^{3 / 2} a_{\mathrm{bl}}^{3}, \quad \tau_{j q}=\frac{a_{\mathrm{bl}}^{2}}{2\left[D_{j}(t)+D_{q}(t)\right]} .
$$

Results of the joint fit of all relevant and available experimental data basing on Eqs. (6), (7) and (9) are shown in Figs. 1-4.
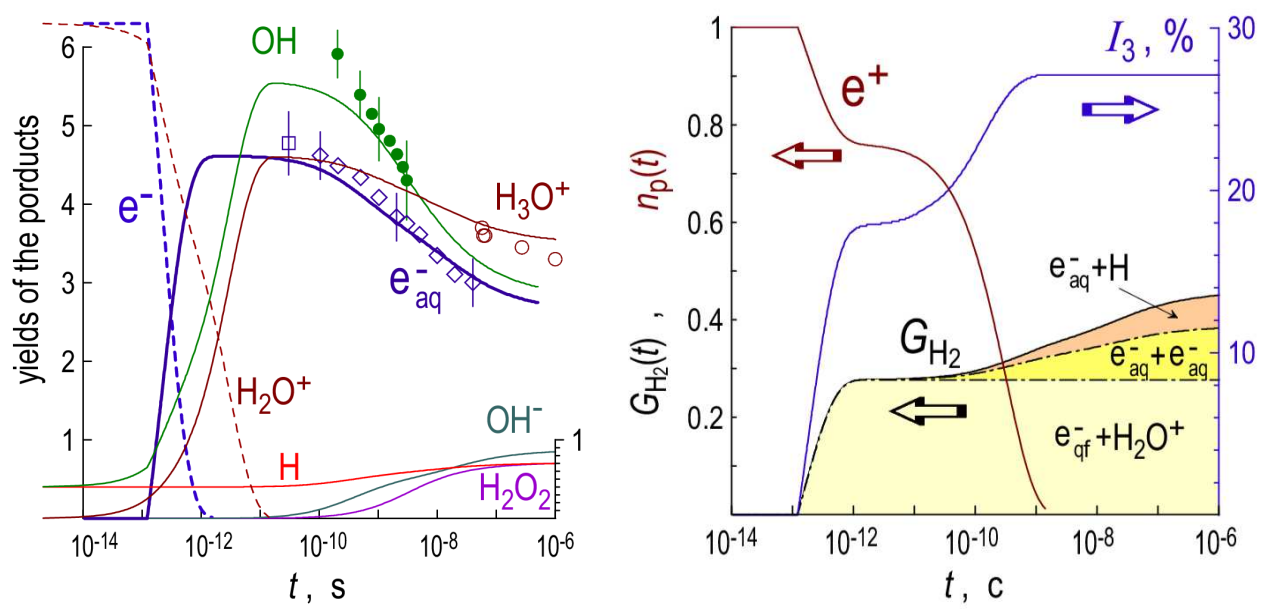

Fig. 2. Kinetics of accumulation of various radiolytic products in neat water at room temperature: $\mathrm{e}_{\mathrm{aq}}^{-}(\square, \diamond-[10]), \mathrm{H}, \mathrm{OH}(\bullet-[11]), \mathrm{H}_{2} \mathrm{O}_{2}, \mathrm{H}_{3} \mathrm{O}^{+}(\mathrm{O}-[8])$, including o-Ps $\left(I_{3}\right)$ and radiolytic hydrogen $\left(G_{\mathrm{H}_{2}}\right)$. Different contributions to $\mathrm{H}_{2}$ formation are shown: $\mathrm{e}^{-}+\mathrm{H}_{2} \mathrm{O}, \mathrm{e}_{\mathrm{aq}}^{-}+\mathrm{e}_{\mathrm{aq}}^{-}$, and $\mathrm{e}_{\mathrm{aq}}^{-}+\mathrm{H}$. All curves present the results of the present calculations.

Following numerical estimations are obtained for:

- non-inhibiting yield of atomic hydrogen, $G_{\mathrm{H}_{\alpha}} \approx 0.4$;

- formation probability of $\mathrm{H}_{2}$ as a result of $\mathrm{e}^{-}+\mathrm{H}_{2} \mathrm{O}^{+\cdot}$ recombination, $f_{\mathrm{H}_{2}}=0.17$;

- duration of the ion-molecule reaction, $\tau_{i \mathrm{mr}} \approx 10 \tau_{\mathrm{e}}^{\mathrm{aq}} \approx 3 \mathrm{ps}$;

- average concentration of ion-electron pairs in the blob $c_{\mathrm{bl}} \approx 0.01$. If we adopt $n_{0}=10$, from $c_{\mathrm{bl}}=n_{0} / V_{\mathrm{bl}}^{0}=n_{0} /\left[(2 \pi)^{3 / 2} a_{\mathrm{bl}}^{3}\right]$ one obtains that initial size of the blob is $a_{\mathrm{bl}} \approx 50 \AA$;

- ambipolar diffusion coefficient for charged intrablob species, $D_{\mathrm{amb}} \approx(2 \div 2.5) \times 10^{-4} \mathrm{~cm}^{2} / \mathrm{s}$, and duration of the ambipolar blob expansion, $t_{\mathrm{amb}} \sim 10^{4} \tau_{\mathrm{aq}} \approx 30 \mathrm{~ns}$

- $\mathrm{e}^{-}$thermalization time, $t_{\mathrm{th}} \approx 0.4 \tau_{\mathrm{e}}^{\mathrm{aq}} \approx 0.12 \mathrm{ps}$;

- numbers for the rate constants of quasi-free $\mathrm{e}^{-}$with various products of radiolysis of water and some $\mathrm{e}^{-}$scavengers (see Table II).

We have found for each scavenger that the value of the product $k_{\mathrm{eS}} \tau_{\mathrm{e}}^{\mathrm{aq}}$ practically coincides with the phenomenological parameter $1 / c_{37}^{-}$characterizing reaction ability of $\mathrm{S}$ with quasi-free electron. Contrary there is no correlation with the rate constant of $\mathrm{S}$ with hydrated electron. 

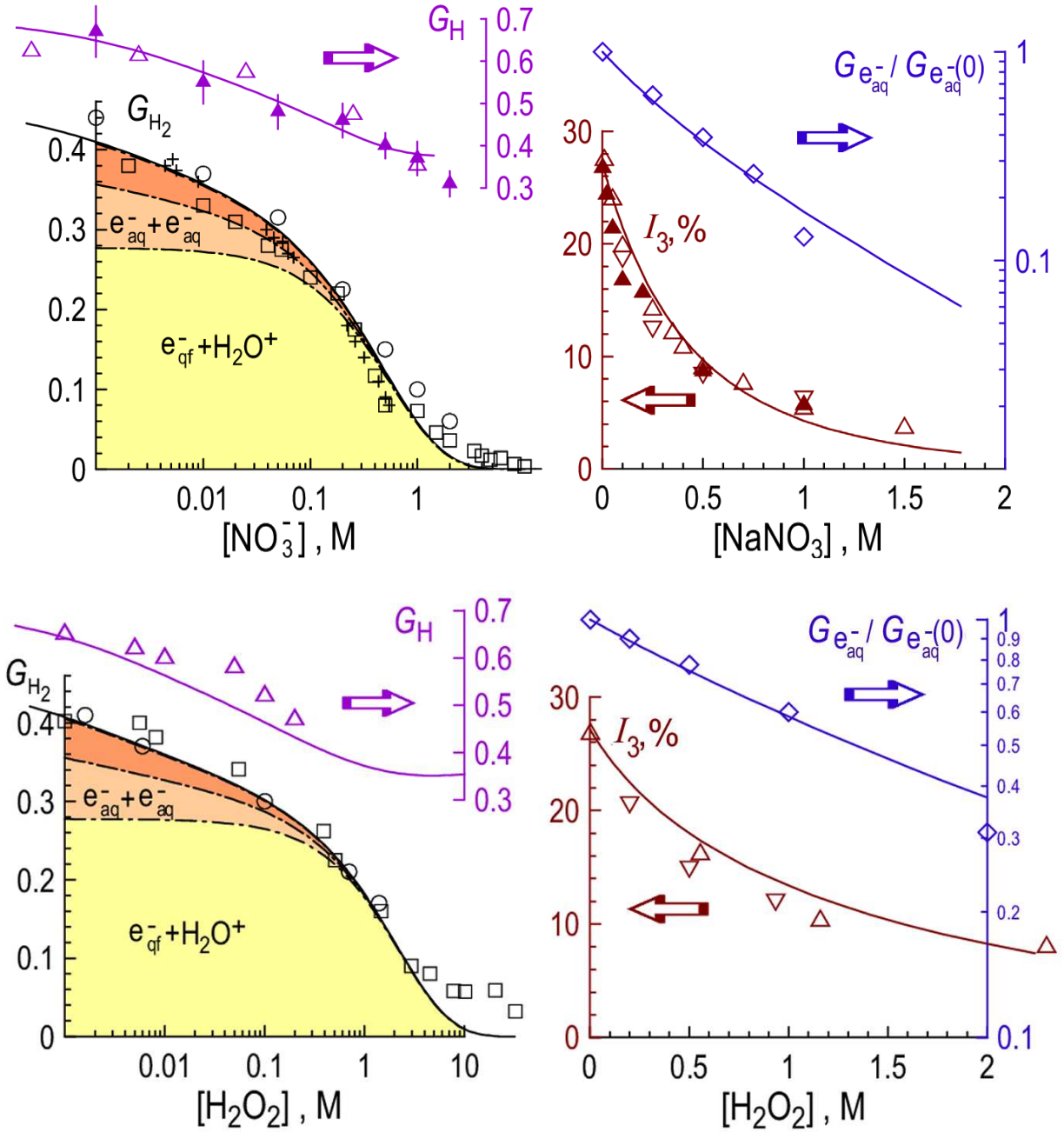

Fig. 3. Comparison of the theoretical and experimental dependences of the yields in aqueous solutions of $\mathrm{NO}_{3}^{-}$and $\mathrm{H}_{2} \mathrm{O}_{2}$. Data on $G_{\mathrm{H}_{2}}\left(\left[\mathrm{NO}_{3}^{-}\right]\right)$are from: $\mathrm{O}-$ [4]; $+-[12] ; \square-[13]$. Data for $G_{\mathrm{H}}\left(\left[\mathrm{NO}_{3}^{-}\right]\right): \Delta-[4] ; \Delta-[5] . G_{\mathrm{e}_{\mathrm{aq}}^{-}}\left(\left[\mathrm{NO}_{3}^{-}\right]\right)$data: $\diamond-[14] . \quad I_{3}\left(\left[\mathrm{NO}_{3}^{-}\right]\right)$data: $\boldsymbol{\Delta}-[15] ; \nabla-[16] ; \Delta-[17]$. Data for $G_{\mathrm{H}_{2}}\left(\left[\mathrm{H}_{2} \mathrm{O}_{2}\right]\right)$ are taken from: $\bigcirc-[18] ; \square-[19] . G_{\mathrm{H}}\left(\left[\mathrm{H}_{2} \mathrm{O}_{2}\right]\right)$ data: $\diamond-[1] . G_{\mathrm{e}_{\mathrm{aq}}^{-}}\left(\left[\mathrm{H}_{2} \mathrm{O}_{2}\right]\right)$ data: $\diamond-[14] . \quad I_{3}\left(\left[\mathrm{H}_{2} \mathrm{O}_{2}\right]\right)$ data: $\nabla-[15] ; \Delta-[20]$. Chain lines demonstrate different contributions to $\mathrm{H}_{2}$ formation: $\mathrm{e}^{-}+\mathrm{H}_{2} \mathrm{O}^{+}, \mathrm{e}_{\mathrm{aq}}^{-}+\mathrm{e}_{\mathrm{aq}}^{-}$, and $\mathrm{e}_{\mathrm{aq}}^{-}+\mathrm{H}$. Solid lines show Eqs. (6)-(9). 

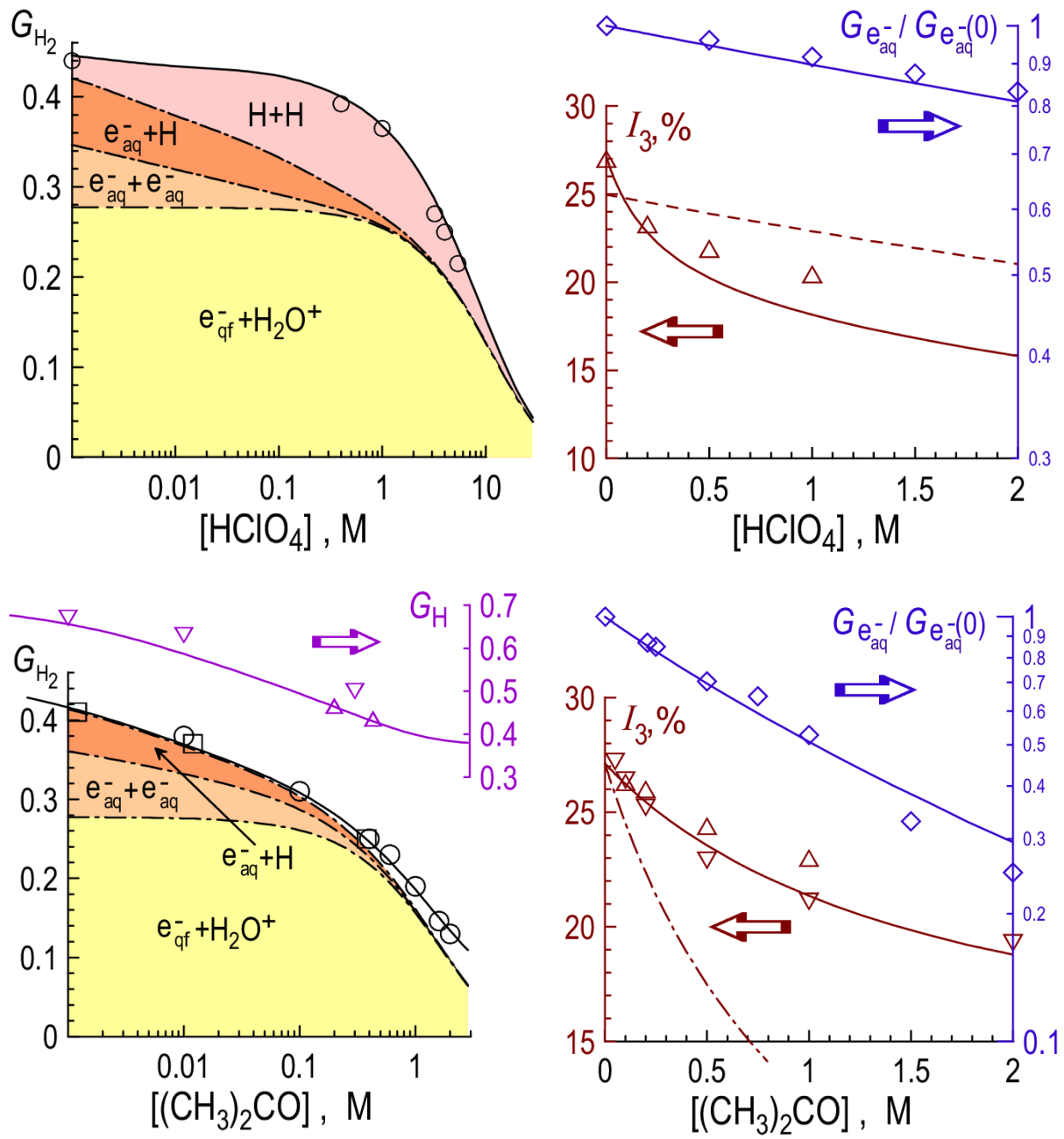

Fig. 4. Comparison of the theory and experimental dependences of the yields in aqueous solutions of $\mathrm{HClO}_{4}$ and acetone. $G_{\mathrm{H}_{2}}\left(\left[\mathrm{HClO}_{4}\right]\right)$ data: $\bigcirc-[21] . G_{\mathrm{e}_{\mathrm{aq}}^{-}}\left(\left[\mathrm{HClO}_{4}\right]\right)$ data: $\diamond-[14] . \quad I_{3}\left(\left[\mathrm{HClO}_{4}\right]\right)$ data: $\Delta-[22] . G_{\mathrm{H}_{2}}([\mathrm{Ac}])$ data: $\bigcirc-[23] ; \quad \square-[6]$. $G_{\mathrm{H}}([\mathrm{Ac}])$ data: $\Delta-[6] ; \nabla-[5] . G_{\mathrm{e}_{\mathrm{aq}}^{-}}([\mathrm{Ac}])$ data: $\diamond-[14] . I_{3}([\mathrm{Ac}])$ data: $\nabla-[24]$; $\Delta-[9]$. Chain lines demonstrate different contributions to $\mathrm{H}_{2}$ formation: $\mathrm{e}^{-}+\mathrm{H}_{2} \mathrm{O}^{+}$, $\mathrm{e}_{\mathrm{aq}}^{-}+\mathrm{e}_{\mathrm{aq}}^{-}$, $\mathrm{e}_{\mathrm{aq}}^{-}+\mathrm{H}, \mathrm{H}+\mathrm{H}$. Solid line $I_{3}\left(c_{\mathrm{S}}\right)$ for $\mathrm{HClO}_{4}$ takes into account contribution of $\mathrm{e}_{\mathrm{aq}}^{-}$to Ps formation and agrees better with experimental data than the dotted line, which ignores this contribution. Chain line for $I_{3}\left(c_{\mathrm{S}}\right)$ in acetone shows theoretical prediction for the ortho-Ps yield without taking into account $\mathrm{e}_{\mathrm{th}}^{+}+\mathrm{Ac}^{-} \rightarrow \mathrm{Ps}+\mathrm{Ac}$ reaction. Corresponding solid line, which goes through experimental points, accounts this contribution. 
TABLE II

Reaction parameters of quasi-free and hydrated electrons with the solutes.

\begin{tabular}{c|c|c|c}
\hline \hline $\mathrm{S}$ & $k_{\mathrm{eS}} \tau_{\mathrm{e}}^{\mathrm{aq}}\left[\mathrm{M}^{-1}\right]$ & $1 / c_{37}^{-}\left[\mathrm{M}^{-1}\right] ;[14]$ & $k_{\mathrm{hS}} \tau_{\mathrm{e}}^{\mathrm{aq}}\left[\mathrm{M}^{-1}\right]$ \\
\hline $\mathrm{NO}_{3}^{-}$ & $2.1(2)$ & 1.9 & $2.8 \times 10^{-3}$ \\
$\mathrm{H}_{2} \mathrm{O}_{2}$ & $0.50(3)$ & 0.55 & $3.3 \times 10^{-3}$ \\
$\mathrm{ClO}_{4}^{-}$ & $0.08-0.09$ & 0.09 & $\lesssim 10^{-7}$ \\
$\left(\mathrm{CH}_{3}\right)_{2} \mathrm{CO}$ & $0.6-0.7$ & 0.67 & $2.0 \times 10^{-3}$
\end{tabular}

\section{Conclusions}

1) A mechanism of formation of the intratrack yields of radiolytic products of water is suggested. For the first time it agrees well with the data on time dependent accumulation of intermediate $\left(\mathrm{e}_{\mathrm{aq}}^{-}, \mathrm{H}, \mathrm{OH}, \mathrm{Ps}\right)$ and final $\left(\mathrm{H}_{2}, \mathrm{H}_{3} \mathrm{O}^{+}\right.$, $\mathrm{OH}^{-}$) radiolytic products as well as with concentration dependences of the yields of $\mathrm{e}_{\mathrm{aq}}^{-}, \mathrm{H}, \mathrm{H}_{2}$, and $\mathrm{Ps}$ in solutions of electron scavengers.

2) We have succeeded to obtain phenomenological "exponential" law of suppression of the initial yield of hydrated electrons and so-called "cube-root" law for the yield of molecular hydrogen, which converts to hyperbolic law $G_{\mathrm{H}_{2}}\left(c_{\mathrm{S}}\right) / G_{\mathrm{H}_{2}}(0) \propto c_{\mathrm{S}}^{-1}$ at large concentration of the scavenger.

3) Account for ambipolar diffusion of charged intrablob species on initial (up to nanoseconds) stage of blob expansion and two ways of intratrack formation of $\mathrm{H}$ atoms are of a principal importance for correct description of the experimental data.

4) The model allows to understand the puzzling $p H$ independence of $\mathrm{H}_{2}$ yield $[5]$

5) The contribution $\mathrm{e}_{\mathrm{aq}}^{-}$to Ps formation is revealed. Account for $\mathrm{e}^{+}+\mathrm{e}_{\mathrm{aq}}^{-} \rightarrow$ Ps (Fig. 4, solid line) gives much better agreement with the experiment.

\section{References}

[1] V.M. Byakov, F.G. Nichiporov, Intratrack Chemical Processes, EnergoAtomIzdat, Moscow 1986 (in Russian).

[2] V.M. Byakov, S.V. Stepanov, J. Radioanal. Nucl. Chem. Articles 210, 371 (1996).

[3] S.V. Stepanov, V.M. Byakov, in: Principles and Applications of Positron and Positronium Chemistry, Eds. Y.C. Jean, P.E. Mallone, D.M. Schrader, World Scientific, Singapore 2003, p. 117.

[4] M. Chourage, J. Sutton, Trans. Faraday Soc. 62, 2111 (1966).

5] Z.D. Draganič, I.G. Draganič, J. Phys. Chem. 76, 2733 (1972). 
[6] A. Appleby, in: The Chemistry of Ionization and Excitation, Eds. G.R.A. Johnson, G. Scholes, Taylor and Francis, London 1967, p. 269.

[7] M. Domae, Y. Katsumura, K. Ishigure, V.M. Byakov, Radiat. Phys. Chem. 48, 487 (1996).

[8] A.K. Pikaev, Modern Radiation Chemistry. Radiolysis of Gases and Liquids, Nauka, Moscow 1986 (in Russian).

[9] V.M. Byakov, V.I. Grafutin, O.V. Ilyukhina, G.G. Myasishcheva, F.G. Nichiporov, S.V. Stepanov, O.P. Stepanova, Yu.V. Funtikov, Khimiya Vysokikh Energii 38, $471(2004)$.

[10] C.D. Jonah, M.S. Matheson, J.R. Miller, E.J. Hart, J. Phys. Chem. 80, 1267 (1976).

[11] T. Sumyoshi, M. Katayama, Chem. Lett. 12, 1888 (1982).

[12] H.A. Mahlman, J. Chem. Phys. 31, 993 (1959).

[13] E. Hayon, M. Maureau, J. Phys. Chem. 69, 4058 (1965).

[14] R.K. Wolf, M.J. Bronskill, J.W. Hunt, J. Chem. Phys. 53, 4211 (1970).

[15] V.M. Byakov, V.I. Grafutin, O.V. Koldaeva, E.V. Minaichev, F.G. Nichiporov, O.P. Stepanova, Preprint ITEP No. 37, Moscow 1984.

[16] R.E. Green, R.E. Bell, Can. J. Phys. 35, 398 (1957).

[17] G. Duplatre, A.G. Maddock, J.-Ch. Abbe, A. Haessler, Radiat. Phys. Chem. 15, 617 (1980).

[18] J.A. Gormley, C.J. Hochanadel, Radiat. Res. 3, 227 (1955).

[19] A.R. Anderson, E. Hart, J. Phys. Chem. 65, 804 (1961).

[20] S.T. Tao, J.H. Green, J. Phys. Chem. 79, 882 (1969).

[21] D. Katakis, A.O. Allen, J. Phys. Chem. 68, 3107 (1964).

[22] V.M. Byakov, V.I. Grafutin, O.V. Koldaeva, E.V. Minaichev, F.G. Nichiporov, Yu.V. Obukhov, O.P. Stepanova, Chem. Phys. 24, 91 (1977).

[23] F.G. Nichiporov, Ph.D. thesis, ITEP, Moscow 1978.

[24] J. Talamoni, J.-Ch. Abbe, G. Duplatre, L. Kawaka, A. Haessler, Radiat. Phys. Chem. 19, 467 (1982). 